\title{
Interactive Meeting for Evidenced-Based Complementary and Alternative Medicines: a Report
}

\author{
Anil K. Gauniyal, A. K. S. Rawat and P. Pushpangadan \\ National Botanical Research Institute, Lucknow 226 001, India
}

The National Botanical Research Institute (NBRI) in association with the Indian Association for the Study of Traditional Asian Medicines (IASTAM) organized an interactive meeting at NBRI on December 6th, 2004 to mark the visit of Professor Edwin L. Cooper, Founding Editor-in-Chief of $e C A M$ and Professor of Comparative Neuroimmunology, Laboratory of Neurobiology, Department of Neurobiology and David Geffen School of Medicine at UCLA, University of California, Los Angeles, CA, USA and Ms Patty Christiena Willis, Founding International Administrator, eCAM, USA and Japan.

Dr Nityanand, Ex-Director, CDRI (Central Drug Research Institute), Lucknow presided over the meeting, which was attended by over 50-60 prominent personalities, representing Ayurvedic- and Unani-practicing doctors, scientists and modern medical doctors, other distinguished scientists working in the traditional medicines, modern medical science and medicinal plants. Prominent among these included: Dr S. K. Jain, Ex-Director, BSI (Botanical Survey of India), India and President of IASTAM; Dr P. Pushpangadan, Director, NBRI and Member of $e C A M$ Editorial Board; Dr Narendra Singh, Ex-Pharmacologist, KGMC (King George Medical College), Lucknow; Dr Shanta Mehrotra, Emeritus Scientist, NBRI, and Member of IASTAM Managing Committee; Dr N. C. Shah, Ex-Senior Scientist, CIMAP (Central Institute of Medicinal and Aromatic Plants), Lucknow; Dr S. S. Shukla, Ex-Principal, State Ayurvedic College, Lucknow; Prof. B. N. Singh, Principal, National Homeopathy College, Lucknow; Dr Janardan Singh, Scientist, CIMAP, Dr A. K. S. Rawat, Scientist, NBRI; Dr S. A. Siddhique, Unani Council, CCRUM (Central Council for Research in Unani Medicine), Lucknow.

For reprints and all correspondence: A.K.S. Rawat, National Botanical Research Institute, Lucknow 220 001, India. E-mail: pharmacognosy1@rediffmail.com

\section{A Brief Overview of Traditional Medicine in India}

Dr P. Pushpangadan, Director, NBRI, in his welcome address introduced the Chairman and paid glowing tribute to the scholarship and scientific pre-eminence of Dr Nityanand, for his endeavours in reviving and revitalizing the traditional system of medicine in India. He further said that in India the traditional system of medicine was very strong and has a long history of 6000-7000 years. He noted that traditional medicines in India function through two streams, the oral traditions practiced by the rural people, who by trial and error selected many plants from their habitat to treat the ailments confronted by them. This stream is called the Local Health Tradition. The other stream organized codified written systems of medicine with their own theoretical and philosophical explanations, such as, Ayurveda, Unani, Tibetan and Amchi systems of medicine. These systems of traditional medicine utilize a large number of medicinal plants. While almost all the medicinal plants used in the organised system of medicines are well researched, most of the medicinal plants used in the local health traditions, particularly those used by the forest-dwelling tribal communities numbering 7-8 million people are yet to be investigated. NBRI is currently engaged in investigating these medicinal plants through either reverse pharmacology or an ethnopharmacological approach. Dr Pushpangadan added that, for Indians, the traditional medicines, particularly Ayurveda, Siddha, Unani and Amchi are mainstream and not complementary or alternative systems of medicines. But there has been erosion and corrosion in the practice of these systems of medicine, and, in addition, they have failed to appropriately inculcate the fast developing science and technology.

\section{The Importance of Terminology: ISM is not Complementary or Alternative}

Dr S. K. Jain, Ex-Director of the Botanical Survey of India and world-renowned ethnobotanist set the interactive meeting into

(C) The Author (2005). Published by Oxford University Press. All rights reserved.

The online version of this article has been published under an open access model. Users are entitled to use, reproduce, disseminate, or display the open access version of this article for non-commercial purposes provided that: the original authorship is properly and fully attributed; the Journal and Oxford University Press are attributed as the original place of publication with the correct citation details given; if an article is subsequently reproduced or disseminated not in its entirety but only in part or as a derivative work this must be clearly indicated. For commercial re-use, please contact journals.permissions@oupjournals.org 
motion. He began by explaining how the Indian Association for the Study of Traditional Asian Medicines was formed in 1980 in Canberra (Australia) and that the Indian Chapter of Indian Medicines, which was formed later, completes its 25 th year in January, 2005, when a large meeting will be held in Pune, India. Since India is such a large country, such preregional meetings should be held periodically, he said. He thanked Dr Pushpangadan profusely for organizing the interactive meeting and welcomed the $e C A M$ journal's Editor-inChief, Professor Edwin L. Cooper, and Ms Patty Christiena Willis, Administrator, eCAM. He spoke of the importance of terminology, expressing the view that complementary, orthodox and alternative have different meanings in different parts of the world. The Indian System of Medicine (ISM) is not complementary or alternative, he opined. He cautioned against quoting these words, often used in foreign journals, since they may have a different meaning in the Indian context. He emphasized the need for standardization of entire traditional systems of medicine and to determine the areas of highest priority, so that our resources could be used to preserve them for posterity. He was of the view that the Indian system of medicine originated from oral traditions.

\section{The Importance of Creating an Interface Between the Traditional and Modern Systems of Medicine}

Dr Nityanand expressed his deep concern on the slow progress of traditional medicines in the Indian sub-continent, even after 50-55 years of effort on various levels. We have not utilized the full benefits of traditional medicines in this part of the world, he said. He further said that even with such vast resources of knowledge, we have not added much in terms of new science, new methods or new developments. He emphasized that the first and foremost requisite is the proper documentation of our vast reservoir of tremendous oral knowledge. He was optimistic that with the initiation of work in this field, documentation could be completed in the next decade, so that the people of India and abroad can use this authentic knowledge. Having done that, the next step would be to transform this traditional knowledge into a workable system that would be beneficial for the masses. For this, he emphasized the need for a proper quality control system for traditional medicines and natural-product-based research. It is easy to work on a single synthetic compound, but in herbal-based products the problems multiplied many fold due to the presence of a large number of active constituents. However, due to the tremendous technological advances in the field of analytical chemistry, proper quality control evaluation systems can be developed. Without going into detail, Dr Nityanand advised that there should be proper markers for quality control of the plants themselves so that they could be properly identified at the genetic, species, cultivar or variety level. He stressed the importance of biological and genomic markers as tools for quality assurance, which can be used in addition to chemoprofiling. We should move to the molecular and system level, and in this direction, institutes like CDRI, NBRI, CIMAP and ITRC could bring about remarkable change. He also discussed the simplification of manufacturing processes and thus pharma-economics with an easy assay system. Touching upon the safety studies, he said that there should be proper safety and evaluation studies and that drug interaction must be taken into consideration as an important component at a very early stage. As far as drug regulatory studies, there has been multiplicity of herbal-based drug manufacturing units in the recent past. These manufacturing units must conform to good manufacturing practices and a proper system of registration should exist. Every drug, anywhere in the world, should first fulfil the pharmacopoeial specifications and only then can the drug be marketed. The increasing popularity and trade of nutraceuticals and herbal drugs all over the world has made these specifications all the more important. He thus suggested that household remedies, nutraceuticals, new herbal drugs and traditional systems of medicine (which have proper pharmacopoeial standards) should come under the review of a registration system. He also discussed the standardization of the agricultural practices. All in all, he emphasized the importance of creating an interface between the traditional and modern systems of medicine.

\section{eCAM: Joint Cooperation to Strengthen Traditional Medicine to Meet the Challenges of Health Care}

Dr Edwin L. Cooper gave a detailed description of the journal Evidenced-Based Complementary and Alternative Medicine $(e C A M)$ and the need for its launch. He was happy to note that the interactive meeting held at NBRI offered an ideal forum for the participants to discuss and deliberate on the important issues of evidence-based complementary and traditional medicine. $\mathrm{He}$ noted that the journal seeks to apply scientific rigor to the study of complementary and alternative medicines modalities, particularly traditional Asian healing systems. Our joint cooperation will help in developing strategies for strengthening the traditional systems of medicine in order to meet the challenges of the imminent health-care needs of humankind. $e C A M$ was launched in a desire to promote the publication of original scientific papers based on firm scientific guidelines, but without any preconceptions against the possible efficacy of new and ancient treatments. This journal has adopted a policy of open access for $e C A M$ papers online. Once the papers have been peer reviewed, they are put online with open access to anyone, a new trend in publishing. This journal emphasizes health outcome, while documenting biological mechanisms of action. The journal is devoted to the advancement of science in the field of basic research, clinical studies, methodology or scientific theory in diverse areas of biomedical studies, he elaborated. Later he illustrated the technical details for preparing a manuscript that would satisfy the requirements for publishing in $e C A M$.

Ms Patty Christiena Willis in her brief introduction also spoke about $e C A M$, her idea for the cover design where the bridge is 
symbolic as a connector to bridging different kinds of cultures and languages, as well as CAM and modern biomedicine.

\section{The West Needs a Deeper Understanding of Ayurveda and Must Respect the Many Aspects of its Science}

Dr Narendra Singh said that the Vedas were the source of infinite knowledge that human beings can draw from the Indian heritage. Ayurveda was the authentic medical system of ancient India. However, over the course of time a lot of literature has been lost and presently only a few Samhintas (treatises) are available. He advocated the development of a database on Ayurvedic medicinal plants that would help to correlate the modern and traditional systems of medicine. He was wary of the fact, and cautioned the WHO and FDA to take note of the way natural products/herbal products are being sold by some multinational companies. He cited the example of Co-enzyme Q10, wherein the product packet claims to be beneficial for reducing cholesterol, amongst other things, but the footnote of the packet reads 'We do not claim it as treatment for any disease', which contradicts all the claims of the product.

Showing his firm conviction and staunch support of Ayurveda and its principals, Dr S. S. Shukla, a retired Professor and Principal of Ayurvedic College, Lucknow (India) and currently a practitioner, was a little bit perturbed by the way plans of action were being mooted out by modern scientists who wanted to bring authenticity to Ayurveda by the amalgamation of modern research for further development. He said rather emotionally that Ayurveda is a fully authentic, organized and systematic knowledge of medicine. Without elaborating, he said that there were certain things, which we (Ayurvedic people) do not accept. He called upon the august gathering to accept the Ayurveda and its spirit in toto. He said that Ayurveda contained every aspect from collection to manufacturing of drugs, however, modern pharmaceutical companies were not applying the Ayurvedic knowledge in its true spirit, and, as a result, the expected results are not achieved. He used the example of Amla (Phyllanthus emblica), fruits which are used in a number of herbal preparations, and noted that they were not being collected in the appropriate time and manner as mentioned in Ayurveda. In Ayurveda, the best timing for the collection of Amla, to obtain the maximum amount of required constituents, is during the months of March and April. Similarly, the best geo-climatic region for the collection of almost all the medicinal plants is the Himalayan and sub-Himalayan region.

Other experts of Ayurveda present at the meeting echoed somewhat similar views. Their common concern was about the relationship between these two widely different scientific systems of knowledge that belong to two different cultural domains. The recent attempts at integration were far from satisfactory, with the modern system of medicine flourishing at the cost of the traditional systems. They cautioned that urgent steps needed to be taken by traditional knowledge systems such as Ayurveda and Unani, for example, in order to gain equal footing in this relatively new area of science, otherwise they would be replaced by the modern systems of medicine. They further said that without full acquaintance with all the fundamental principles of Ayurveda, followers of modern science could not understand and appreciate the scientific authenticity of the claims of Ayurveda's system of medicine.

\section{The Revival of Indigenous Systems of Medicine will Require the Synergy of Research Work in Modern and Traditional Systems of Medicine}

Dispelling the conflict of views and concern of Ayurveda experts towards modern scientific research vis-à-vis Ayurveda and other traditional systems of medicines, Dr Pushpangadan, Director, NBRI, said that science augurs continuous development and if further research work were not done in this area, Ayurveda would have to draw on its original dynamism, without which it would remain stagnant and eventually collapse in the due course of time. Citing certain Sanskrit slokas (verses) from Ayurveda, Dr Pushpangadan asserted that Ayurveda was not only limited to bodily or physical symptoms but it was a philosophy, which gave us a comprehensive knowledge about physical, spiritual, mental and social health. Thus Ayurveda was one of the oldest systems of health care, dealing with both the preventive and curative aspects of life in a most comprehensive way. He further said that the remedies found in all cultures of the world have evolved by trial and error, eventually leading to the emergence of the science of traditional medicines. However, with the discovery of a number of novel synthetic chemical drugs, the emphasis has shifted from the traditional systems to modern medicine. Somewhat, similar views were also addressed by Dr Nityanand, who said that Ayurveda was a science in the sense that it was a qualitative, holistic science of health and longevity, and a system for healing the whole person, body and mind. However there is an urgent need for the revival of indigenous systems of medicine, which will require the synergy of research work in modern and traditional systems of medicine.

Dr Shanta Mehrotra gave an overview of the status of work being carried out in the indigenous system of medicine and natural product development at NBRI, Lucknow. The Pharmacognosy and Ethnopharmacology division of NBRI has been recognized as a drug testing centre for ASU drugs and more than 160 single herbal drugs and a number of herbal formulations have been standardized by this laboratory.

Dr N. C. Shah spoke on the relevance of oral traditions and ethnic food to local health tradition in Uttaranchal and other parts of India. He highlighted the importance of therapeutic knowledge for the preparation of ethnomedicine, explaining the mode of administration and dosage along with promising biological activities of some ethnomedicinal plants/preparations, such as Ocimum sp, Elusine coracona (Koda) grains, Cannabis sativa (Bhang seed), Trigonella foenum-graecum seeds (Methi seeds), Glycine max seeds, and panzeeri (a powder made out 
of a number of ingredients of medicinal plants mixed with supplementary food, which is very effective for post-natal healing and bringing strength to new mothers). He expressed the need for testing these simple herbal medicines used for high profile diseases to establish their utility as medicines.

Dr S. A. Siddhique of Unani Council, CCRUM, Lucknow said that we were here for the benefit of humanity and therefore our approach should be holistic. The Unani system of medicine has been a well-recognized system of medicine in India for hundreds of years and is actually a synthesis of philosophical views, experiences and cultural influences of many countries, he said. The Unani system of medicine came to India 200 years ago, yet the knowledge has not been fully shared. Citing a few examples he described some of the differences between the Unani system and Ayurvedic system, e.g. Lac [a secretion of an insect (Lacifera lacca)] is taken orally in the Unani system, while in the Ayurveda medicine, it is topically applied.

There was an open forum wherein many Ayurvedic doctors expressed their anguish at the distortion of Ayurveda by modern scientists without full understanding and lack of involvement by Ayurvedic experts. There was a consensus among the Ayurvedic and Unani doctors/experts that more of such meetings needed to be held. To this, Dr Pushpangadan agreed that, with the launching of the $e C A M$ journal and NBRI's association with its editorial board, NBRI will organize more such meetings to bring the two systems of medicines to a better understanding and appreciation of each others' views and thereby forge a strong bond and harmony to support the traditional medicines best suited to the health-care needs of human kind.

\section{Problems Confronting Indigenous Herbal Medicines}

All the participants unanimously expressed their great concern about the loss of quality of the Indian system of medicines and its poor performance in the global market. After an animated debate, the participants identified the following problems confronted by indigenous herbal medicines.

- Reluctance of the practitioners of indigenous systems of medicine to accept and assimilate modern scientific methods and tools in the pre-harvest to post-harvest processing of medicinal plants and standardized procedure for preparation of herbal formulations/herbal drugs.

- Failure to ensure consistency in batch-to-batch production of herbal drugs/formulations and consequent failure to compete at the international level.
- Inadequate standardization methods/tools.

- Lack of systematic documentation of herbal products.

- Rarity and danger of extinction of medicinal plant species from their natural ecosystems due to various anthropogenic activities (almost $85 \%$ of the medicinal plants required for the preparation of traditional remedies are collected from natural resources).

\section{Steps to Overcome these Problems}

To overcome the aforesaid problems it was suggested that, as far as possible, an integrated research approach should be followed to make the best use of traditional knowledge while using the modern tools and technology for optimal utilization of the valuable resources of our wealth of medicinal plants.

This should be done by:

- Sharing and networking the information or creating inventories for the traditional remedies.

- Formulating policy guidelines for establishment of different parameters and procedures that best suit herbal remedies in order to fix the standards of raw drugs and finished products using pharmacognostic, chemotaxonomic molecular DNA fingerprinting and reverse pharmacology techniques, or guidelines for assessing the safety, efficacy and batch-to-batch consistency of herbal products/drugs.

- The manufacturing process should follow GMP compliance by being efficient, time and cost effective, with the development of in-process controls.

- Regulatory issues to be followed for manufacturing units.

- Registration of herbal products, viz., household remedies, herbal drugs, nutraceuticals, and traditional system remedies as separate entities.

- Study the mode of action of drugs at the cellular, molecular (receptor level) and system levels, having as holistic a view as possible. The validation of Ayurvedic and ethnobotanical claims using modern scientific methodology along with current professional practices.

- Availability/cultivation of important medicinal plants and standardization of post-harvest technology.

- Concentration should be made on therapeutic categories, viz. development of herbal products for chronic ailments, adaptogens, immunomodulators, rheumatic disorders, degenerative diseases of old age, cancers, liver problems and diabetes, within the broad basic concepts and philosophy of Ayurveda.

Received January 19, 2005; accepted February 9, 2005 


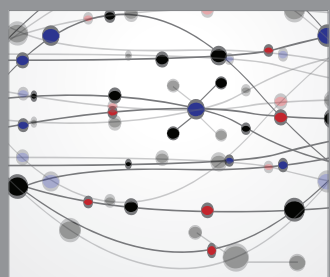

The Scientific World Journal
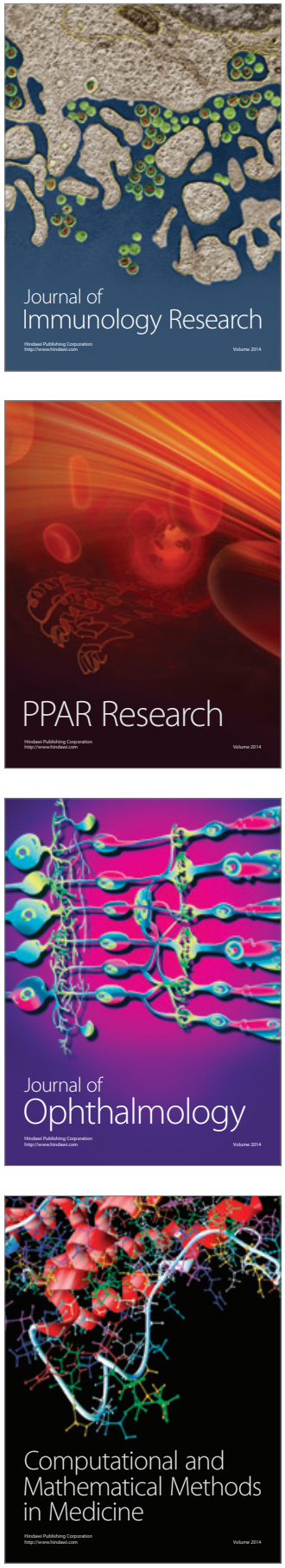

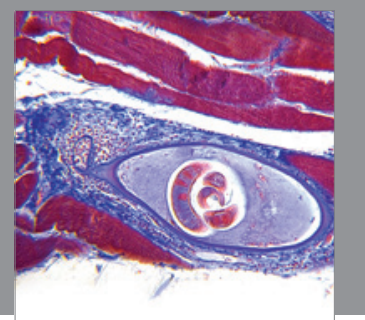

Gastroenterology

Research and Practice
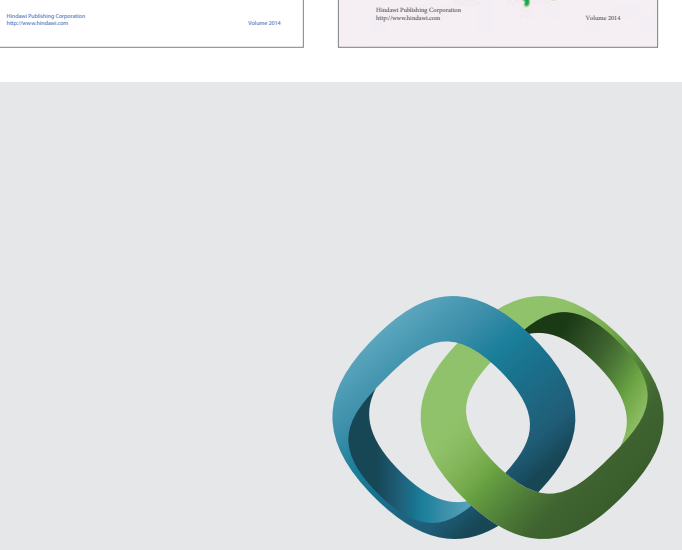

\section{Hindawi}

Submit your manuscripts at

http://www.hindawi.com
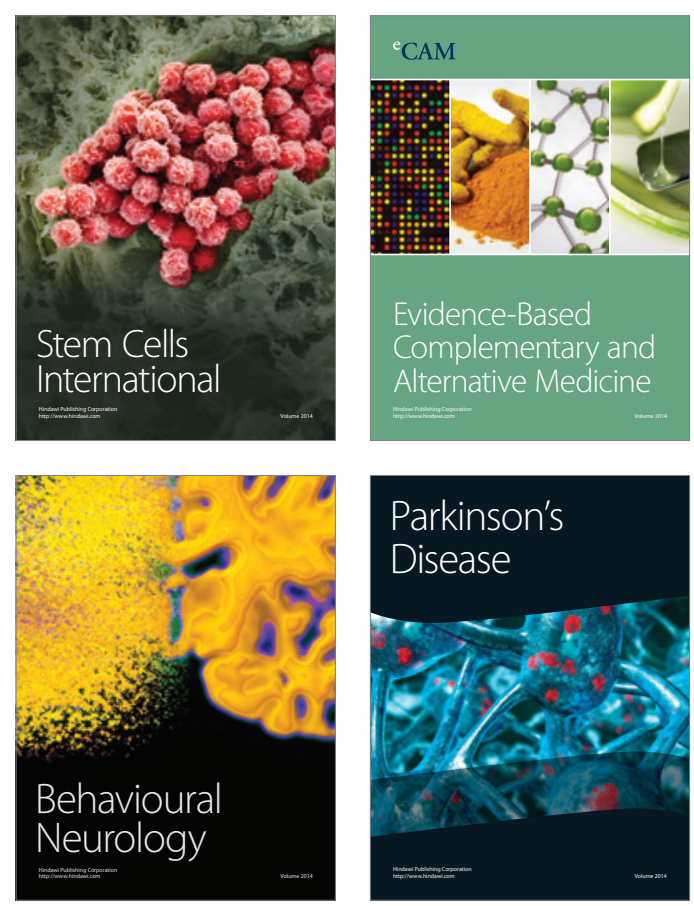

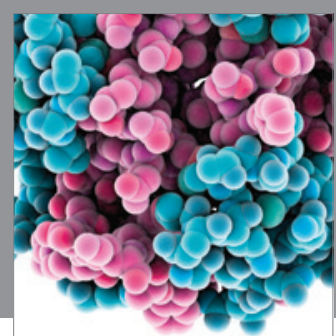

Journal of
Diabetes Research

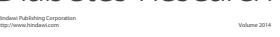

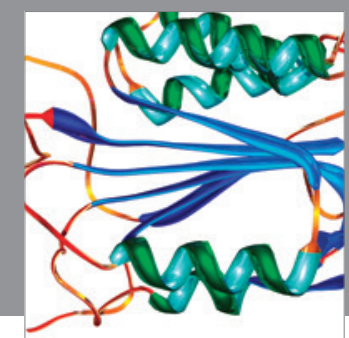

Disease Markers
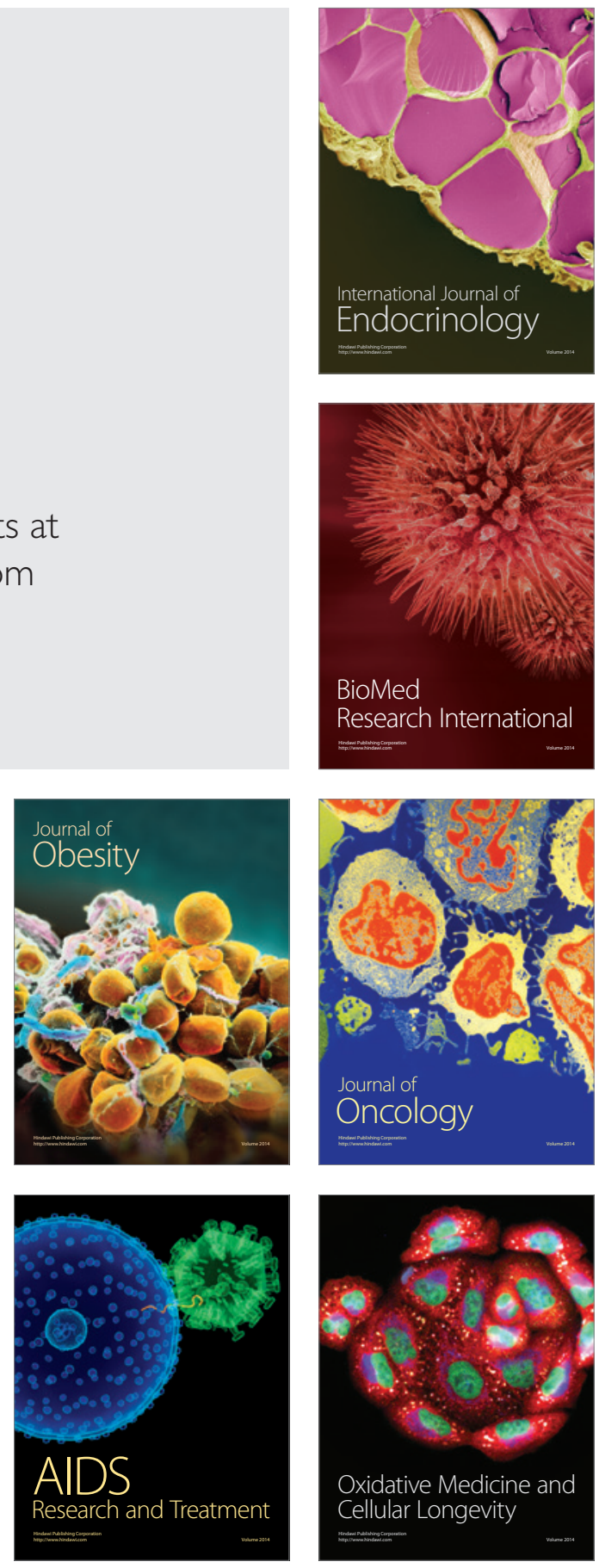